\title{
The Effect of Affective Self- Regulation Training Workshop on Academic Achievement in Emergency Medical Students in Higher Diploma
}

\author{
1 Masoumeh Otaghi \\ 2 Reza Valizadeh \\ $3^{*}$ Sattar Kikhavani \\ ${ }^{1}$ Faculty of Nursing \& Midwifery, Ilam University of Medical Sciences, Ilam, Iran \\ 2, 3 Faculty of Medicine, Ilam University of Medical Sciences, Ilam, Iran \\ * Corresponding Author; Email: skaikhavani@yahoo.com
}

\section{Doi:10.5901/mjss.2016.v7n4s2p11}

\begin{abstract}
The aim of this research was determining the Effect of Affective Self- Regulation Training Workshop on Academic Achievement in Emergency Medical Students in Higher Diploma in llam University of Medical Sciences. This interventional study with prepost test design without control group was a part of an action research greater study for directing and implementing an educational process. The intervention included three- hour's two educational workshops of "improving self esteem" and "success laws" that were taken for 23 students in their third term in 2015. Data gathering were done by valid and reliable questionnaires of self esteem of Cooper Smith and fear of success of Good. Data analyzed by descriptive and inferential (tpaired) statistics in SPSS21. Mean of the self esteem increased from 32.76 \pm 5.37 before intervention to $38.14 \pm 4.77$ after intervention $(p=0.001)$. Mean of the fear of success decreased from $12.57 \pm 3.85$ before intervention to $9.90 \pm 2.02$ after intervention $(p=0.001)$. Average marks of these students decreased from second term to third term; but wasn't significant $(p=0.058)$. Their average marks increased from first term to third term $(p=0.03)$. Workshop education of self esteem and success laws by the advisor led to increasing self esteem, decreasing fear of success and relatively improving the academic achievement of the students of Emergency Medical in higher diploma. Considering the importance of affective domain in selfregulated learning as an essential element in motivation and acceleration of students learning as well as the facilitator role of the advisor in this regards, carrying out these workshops and the same in affective domain of self- regulated learning were proposed.
\end{abstract}

Keywords: self esteem, fear of success, affective self regulation learning, academic achievement

\section{Introduction}

Learning is one of the most important subject in today psychology fields and nevertheless one of the most difficult concepts for defining. The most famous definition of learning is: "creating relatively permanent behavioral change or potential behavior due to experiment not to temporary conditions such as illness, fatigue and drugs" (Hergnehan, 2011). Learning activities were put in three domains of cognitive, affective and psychomotor. This taxonomy that developed by Bloom et al, emphases on their special features, not differentiate them in the separate and irrelevant categories completely. Since it can't be determined a border among these three domains in educational activities. So these domains aren't separate but spin in a united, connected and interweave grid. But each of them should be assessing separately for studying or reinforcing (Shabani, 2004). In fact, each domain specifies the piece of knowledge perspective. Learning taxonomy tries to mapping that perspective and creates categories for describing the ways of knowing; just as a map for describing the land (Mccahan \& Ramkey, 2011).

Learning is a personal process and the student is the person who experiences the learning. The duty of instructor is designing and preparing the appropriate activities for facilitating learning (Imani \&Tajalli, 2015). Training of selfregulated learning is one of the appropriate educational programs. Self- regulating have the valuable outcomes in learning process, education and even the success in life and is one of the considerable concepts in cotemporary education and training. The essential framework of self- regulated learning theory is based on how individuals organize their learning on the meta- cognitional, motivational and behavioral beliefs (Nakhostin Goldust \& Moumenikiia, 2009). Extensive researches on how well learners understand and apply the scientific method, have shown self- regulated learners encounter significant challenges in designing and validly interpreting of their experiments (Winne, 2010). Self- 
regulating is an important aspect of student learning in academic performance. Self- regulating learners are automatic, feedback and efficient (Wolters, 2003). When students demonstrate lack of willpower or skills for academic achievement, they need to educational approaches for showing the direction and providing the insight onto self- regulated learning processes. In this regard, it must be note to develop all three dimensions of metacognitive, motivational and behavioral of self-regulated learning (Zimmerman, 1990).

Theory and research on self-regulated learning started from the mid-1980s and Self-regulation have been be attention of psychologists, counselors and educators as a new strategy to help students to master the learning processes and generally improve the quality of learning (Derakhshan Horeh, 2010). Until the 1980s, the studies in the field of selfregulated learning focused on various personal, family and social aspects and after that, this construct was raised in the context of learning and was considered by various theories of psychology such as behaviorism, cognitivism and constructivism (Kadivar, 2003). A meta-analysis with 109 reviews showed that the psychological factors and study skills predict academic outcomes (Robbins, Lauver, Le, Davis, \& Longley, 2004). In a study was conducted on 952 freshmen students of psychology, a model of the effectiveness of self-regulated learning developed and tested. This model included success goals, metacognition, study strategies and academic achievement (Vrugt \& Oort, 2008). The studies on academic achievement show the components of cognitive and metacognitive strategies, effort management, cooperation and seeking help in learning affected on students' academic achievement (Abolghasemi \& Mirali Rostami, 2001). The academic achievement of students also can be increased by reinforcement of the achievement motivation (Noohi, Hosseini, Rokhsarizadeh, Saburi, \& Alishiri, 2010).

Park \& Confessore in 2007 have provided an interactive model of educational development that in fact, is on the basis of self-education. They state several psychosocial issues affect on the individual willingness to learn. The three areas are: Change and learning (including individual, economic, social or professional changes in the life), environmental factors and student awareness of models and purposes of learning activities (Park \& Confessore, 2007). In our country, research and interventions have been taken in the field of empowerment of students in each of the domains of learning including the study in the cognitive and affective domains that have shown the affective self-regulation and study skills correlate with academic performance of students (karimi \& farahbakhsh, 2012). In general, self-regulation is very important to understand and control the learning and the success in teaching materials as well as make the learners to efficient and effective learners (Scraw \& Brooks, 2000). Students must play an active role in their learning, learn to assess their learning and use the new strategies if it was not successful learning strategies (Sadeghi \& Mohtashami, 2011). In medicine, the ability to lead and set individual learning experiences, is a very important issue for success and self-directed learning skills that are relevant to lifelong learning are very important. These skills will also help to college students in acquisition of unique knowledge, skills and attitudes in their personal and professional growth. So empowering the students for acquiring the necessary skills for self-directed learning should be one of the ultimate goals of the educational curriculum (Soltani Arabshahi \& Naeimi, 2013). As well as the studies and researches in recent decades have noted the effectiveness of guidance and counseling student and the emphasis on training academic skills in the form of training workshops or presenting lesson courses at the beginning of admission to universities (Valizadeh, Fathi Azar, \& Zamanzadeh, 2008; Badeleeh, Hosseini, Charkazi, Jafari, \& Bakhsha, 2013; Badeleh, Hesam, Charkazi, Asghari, \& Khorsha, 2012; Torabi, Haghani, \& Mosavi, 2014; Rouhani, akbar, \& Mamavi, 2009). It is necessary to train learning strategies to the clients in counseling and educational planning, and explain how to apply them by consultants (Derakhshan Horeh, 2010). Therefore this study aimed to determine the effect of affective self-regulation training workshop on educational achievement in emergency medical students in higher diploma.

\section{Materials and Methods}

This study was a part of an action research greater study for directing and implementing an educational process. This action research was taken on 23 students of medical emergency in higher diploma entrance January 2014 in order to develop their learning skills through self-regulation strategies during three courses of 4 months ( 3 semesters). The plan of the study was formed when low GPA for the semester, academic problems, failing some students in the course and lack of motivation for academic achievement were identified by reviewing the educational records of students by advisor in the end of the first semester (July 2014). Strategies to solve these problems were considered by reading books and magazines, and in consultation with other partners. Finally, the solution of "Group training of self-regulation skills for developing learning skills of the students" was selected based on the ease of implementation, the possibility of more efficient with time-saving, cost-effectiveness for students and educational system, relying on the positive effects of group, less need for coordination between sectional and multi-sectional educational system and the use of personal experience as a consultant and lecturer researcher. The educational intervention was considered the implementation of one or two 
workshops every semester (depending on time, weekly programs for students and advisor and faculty facilities) in the field of self-regulation skills in cognitive, affective and behavioral learning domains by holding pre and post tests.

The present study was designed with interventional pre-post test design without control group. Two 3-hour workshops entitled "Improving self-esteem" and "Laws of Success" were held by the Advisor during the third semester of the students (January 2014). 21 of 23 students attended both workshops. The content of improving self-esteem workshop included self concept and its components (body image, self-esteem, ideal self, role play and individual identity), sources of self-esteem, Specifications of individuals with low and high self-esteem, factors affecting self-esteem and promoting self-esteem. Also, seven indicators of the inferiority complex were discussed: Sensitivity to criticism, inappropriate reaction against servicing, more critical attitude, and willingness to blame, abuse feelings, and negative feelings about the competition, the tendency to isolation and shyness (Ganji- a, 2005; Ganji- b, 2005; Ganji- c, 2005). The content of laws of Success workshop included twenty laws of having big dreams, determining the direction and purpose, sovereignty over his own destiny, doing favorite work, working excellent, long and hard, preparing for lifelong learning, professional learning all the details and content requirements, self dedication to serve others, complete honesty with self and others, focusing on the most important priorities of life, having speed and reliability, readying to conquer the summits of success, practicing self-discipline, unlocking creativity, communication with honest people, caring his health, assertiveness and purposeful follow up, no fear of failure and having perseverance.

Pre and post-test of workshop were taken through questionnaires of Cooper Smith self esteem and Good fear of success. Pre test before the workshop and post-test a month after the workshop was taken. The Cooper Smith self esteem questionnaire contains 58 questions in which yes answers in 19 questions and no answers in 31 questions have one score and 8 questions also related to the lie detecting. For people who got 4 from 8 scores of lie detecting, the test was performed again. In calculating the rates of self-esteem, who their scores were higher than 25 , had high self esteem and who their scores were lower than 25 , had low self esteem. This questionnaire widely used in psychological researches. Its credibility and reliability mentioned high in recent years in Iran (Pourfarajei, 2001, Sabet, 2006; Heydarei, Pasha, \& Atashpoor, 2005; Javanbakht, Ziaee, Homam, \& Rahnama, 2010; Moradei Shahrebabak, Ghanbari Hashemabad, \& Aghamohmmdeian Sherbaf, 2011). The scale of fear of success has 29 items that answered with yes or no. This test has normalized on students with 18 to 30 years. Numerous studies have confirmed its validity and reliability. The score of the scale is closer to 29; the fear of success is more (Pourfarajei, 2001).

Statistical analysis of data was performed in software SPSS21through descriptive (frequency tables, mean and standard deviation) and inferential statistics using paired t-test. Academic achievement was measured by their semester GPA.

\section{Results}

Demographic characteristics of the participants showed all participants were male and single $(n=23)$, between the ages of 19 to 28 years with a mean of $21.43 \pm 2.31$. 4 people were inhabitant of llam, 16 people were living in the state of llam and 3 people were living in other states of the country.

Table 1 show that the mean score of self-esteem reached from $32.76 \pm 5.37$ before intervention to $38.14 \pm 4.77$ after intervention. Mean score of fear of success reached from $12.57 \pm 3.85$ before intervention to $9.90 \pm 2.02$ after intervention. Therefore the training workshop on self-esteem and the laws of success, increase the self-esteem of students and reduce their fear of success $(p=0.001)$.

Table 2 shows that the implementation of these interventions has not affected on academic achievement from second to third term in students of medical emergency in higher diploma; but has affected on the highest and lowest class average. The GPA of students has reduced in the third semester than the second. However, this reduction was not statistically significant $(p=0.058)$. as well as the table shows the GPA of the students has been a significant increase from the first semester to the third $(p=0.03)$

Table 1. Comparison of self-esteem and fear of success before and after intervention

\begin{tabular}{|l|c|c|c|}
\hline \multicolumn{1}{|c|}{ Phase } & $\begin{array}{c}\text { Before } \\
\text { Mean } \pm \text { SD }\end{array}$ & $\begin{array}{c}\text { After } \\
\text { Mean } \pm \text { SD }\end{array}$ & P \\
\hline self-esteem & $32.76 \pm 5.37$ & $38.14 \pm 4.77$ & $0.001^{*}$ \\
\hline fear of success & $12.57 \pm 3.85$ & $9.90 \pm 2.02$ & $0.001^{*}$ \\
\hline
\end{tabular}


Table 2. Comparison of academic achievement based on GPA before and after intervention

\begin{tabular}{|l|c|c|c|c|}
\hline Term & Maximum & Minimum & Mean \pm SD & P \\
\hline First & 17.42 & 12.43 & $15.05 \pm 1.23$ & \multirow{2}{*}{$0.03^{*}$} \\
\hline Third & 18.01 & 13.84 & $15.46 \pm 1.22$ & \multirow{2}{*}{0.058} \\
\hline Second & 17.91 & 13.49 & $15.75 \pm 1.29$ & \multirow{2}{*}{ Third } \\
\cline { 1 - 4 }
\end{tabular}

\section{Discussion}

Workshops training on self-esteem and laws of success increased self-esteem of the students. Increasing self-esteem among students, prepare them to enter the workplace in the future. Abedi and colleagues did a study entitled "Experiences of nursing graduates of professional preparedness during the transition to their clinical role". The findings of this qualitative study were presented in four themes: Professional competence, confidence, colleagues' expectations and emotional adverse reactions. The results of this study that were concrete experiences of participants, showed many of the participants have experienced a lack of readiness for entering the workplace. The authors have suggested a suitable solution for the transition from student to professional role is providing appropriate educational programs while studying at university. This will enable graduates to more readily into the working environment (Abedi , Heidari, \& Salsali, 2004). One of these appropriate teaching programs in this field is the self-regulated learning training (Nakhostin Goldust \& Moumenikiia, 2009). Conducting workshops on self-esteem and laws of success was in the direction of affective selfregulated training and can be effective in this regard.

Training workshop on self-esteem and laws of success reduced the fear of success of the students. Knowledge of laws of success in education, work and life is a kind of meta-cognitive knowledge. This meta-cognitive knowledge helps to self-regulation and control of fears, concerns related to success and having a sense of mastery and self-control. Vrugt and Oort did a Research entitled " Metacognition, achievement goals, study strategies and academic achievement: pathways to achievement" on 952 freshmen of psychology at the University of Amsterdam aims to develop and test the effectiveness model of self-regulation. The model included the success goals (mastery goals and objectives to avoidingdoing), metacognition (knowledge of metacognition, set and experience), study strategies (metacognitive strategies, deep cognition, superficial cognition and resource management) and academic achievement. In the model, relationship with controlling intelligence ability, gender and age were tested. The results showed that self-regulated learning is effective in two paths: The cognitive and strategic paths. The first path involves a positive relationship of mastery goals and a negative relationship of objectives of doing- avoiding with metacognition. Metacognition affected on four study strategies positively. Strategic path included the positive effects of mastery goals and the goals of doing- avoiding the use of metacognitive and deep cognitive strategies. Moreover, the goals of doing- avoiding affected positively on the use of superficial cognitive and resource management. Use of metacognitive strategies and resource management had positive effects and use of superficial cognitive strategies had negative effects on test scores (Vrugt \& Oort, 2008). As well as the awareness of students of the laws of success affect on their attitude and motivation. A study in Hong Kong showed clear differences between study strategies and learning of students who had higher academic achievement than other students. In the study, attitude and motivation were the main factors that distinguished the successful from unsuccessful students (Yip, 2007).

Although self-esteem training and the laws of success workshops increase the self-esteem of students and decrease their fear of success, but have not affected on their academic achievement from the second semester to the third and only effected on increasing the highest and lowest class average. The study on 313 students of Isphahan University of medical sciences in 2012 showed the affective self-regulation and study skills correlate with academic performance of students significantly (karimi \& farahbakhsh, 2012). It seems affective development is a continuous and gradual process. Therefore, in this study performance improving outcomes and academic achievement is not specified in the short term due to the gradual impact of education in affective domain. Also in this study, only two strategies were used for affective self-regulation and other strategies for affective self-regulation may use by the students or be appropriate for them. Another reason was reducing the average scores of students due to the effects of very low scores or even rejection of students in some courses, such as expertise English language that need to have a strong base and was not corrected in the short term. However, the GPA of these students increased significantly from the first semester to the third, which can be related to the overall impact of training program of self-regulation skills on their academic achievement. 


\section{Conclusion}

The results showed that workshop training of self-esteem and laws of success by the advisor increased self-esteem, decreased fear of success and improved relatively academic achievement of students of medical emergency in higher diploma. Given the importance of the affective domain in learning as an essential element in motivating and accelerating student learning as well as the facilitator role of advisor in this regard, running these and similar workshops in the fields of affective domain in self-regulated learning is ecommended.

\section{Acknowledgement}

Thanks to the cooperation of the faculty of Nursing and Midwifery, Medical Education Development Center of llam university of Medical Sciences and the students of medical emergency in higher diploma entrance January 2014 for implementation of this research.

\section{Ethical Approval}

This article comes from a research project which approved by Medical Education Development Center of llam university of Medical Sciences with code 910530.

\section{Funding Resources}

This article comes from a research project of education in research which approved by the llam University of Medical Sciences and supplied and sponsored by the research assistance of llam University of Medical Sciences.

\section{References}

Abedi, HA., Heidari, A., \& Salsali, M. (2004). New graduate nurses' experiences of their professional readiness during transition to professional roles. Iranian Journal of Medical Education, 4(12): 69-78.

Abolghasemi, M., \& Mirali Rostami, O. (2001). Assessment of influencing factors of academic achievement of students in Tehran University of Engineering to present a model of predicting their academic achievement. Iranian Journal of Engineering Education, 15 (58):67-84.

Badeleeh, MT., Hosseini, SA., Charkazi, A., Jafari, SY., \& Bakhsha, B. (2013). The relationship between students' study skills and academic achievement. Iranian Journal of Medical Education, 13(1):66-71.

Badeleh, MT., Hesam, M., Charkazi, A., Asghari, SZ., \& Khorsha, H. (2012). Study skills in nursing and midwifery students of golesatn university of medical sciences. Journal of Research Development in Nursing \& Midwifery, 9 (1):34-40.

Derakhshan Horeh, Kh. (2010). Self Regulated Learning. Educational Technology, 2(26):27-29.

Ganji, H. (2005). Self esteem Questionnaire, Revised Form of Cooper Smith Questionnaire. Tehran: the Center of Psychometrics Publication.

Ganji, H. (2005). Personality evaluation. Tehran: SAVALAN.

Ganji, H. (2005). Fear of success Scale. Tehran: the Center of Psychometrics Publication.

Hergnehan, BR. (2011). An Introduction to theories of learning. 8th ed. Tehran: AGAH publication.

Heydarei, A., Pasha Gh, R., \& Atashpoor, S. (2005). Prevalence of eating disorders and their association with self-esteem, self-concept and depression in female students of lelam university. Knowledge \& Research in Applied Psychology, 26: 1-16.

Imani, A., \&Tajalli, S. (2015). Clinical Teaching Strategies. Tehran: ANNATEB publication.

Javanbakht, M., Ziaee, SA, Homam, SM., \& Rahnama, A. (2010). Effect of Ramadan fasting on self esteem and mental health of students. Journal of Fundamentals of Mental Health, 11(4): 266-73.

Kadivar, P. (2003) Educational psychology. Tehran: SAMT.

karimi, M., \& farahbakhsh, K. (2012). Relationship between affective self-regulation and study skills with educational performance of students of Isfahan University of Medical Science. Iranian Journal of Medical Education 11 (9):1149-1161.

Mccahan, S., \& Ramkey, L. (2011). Beyond Bloom's: Useful constructs for developing graduate attribute indicators. in proc. ${ }^{2 n d}$ Annual CEEA Conf. S.T. John's N.L, 6-8 June 2011.

Moradei Shahrebabak, F., Ghanbari Hashemabad, BA., \& Aghamohmmdeian Sherbaf, HR. (2011). The survey of Effectiveness of the treatment Reality Therapy in group way to increase students' self-esteem. Studies in Education and Psychology, 11 (2):227-38.

Nakhostin Goldust, A., \& Moumenikiia, M. (2009). The study of relation between self-regulated learning strategies and motivation strategies for learning with educational performance of students of Ardabil Islamic Azad University. Curriculum Plan Knowledge Res Educ Sci, 23(23):85-100.

Noohi, S., Hosseini, M., Rokhsarizadeh, H., Saburi, A., \& Alishiri, GH. (2010). Progress motivation among Baqiyatallah University of 
Medical Sciences students and its relationship with academic achievement. Iranian Journal of Military Medicine, 14(3):200-204.

Park, EM. \& Confessore, GJ. (2007). An Interactive Model of Instructional Development. International Journal of Self-directed Learning, $4(2): 38-51$

Pourfarajei, F. (2001). Comparison of academic performance and Physical male students lacking And meet the fathers the moderating role of social support with Intelligent control, self-esteem, lack of long-term and socioeconomic condition their families in the first grade school in Ahvaz city. [MS Thesis]. Department of Educational Sciences: SHAHID CHAMRAN University. Ahvaz, Iran.

[11] Robbins, ST., Lauver, K., Le, H., Davis, D., \& Longley, R. (2004). Do Psychosocial and Study Skill Factors Predict College Outcomes? A Meta-Analysis. Psychological Bulletin, 130(2): 261-288.

Rouhani, A., akbar, M., \& Mamavi, T. (2009). Evaluation of Study Skills among Student of Mashhad Dental School in Academic Year 2008-2009. Teb Va Tazkieh, 19(4):63-73.

Sabet, M. (2006). survey of validity, reliability and Normative Self Esteem test cooper smite in Tehran nineteen branches of education.[MS Thesis]. Tehran: ALLAMEH TABATABAI University. Tehran, Iran.

Sadeghi, Z., \& Mohtashami, R. Role of Meta-cognition in learning process. Bimonthly Educ Strateg Med Sci, 3 (4) :143-148.

Scraw, G. \& Brooks, D. (2000). Helping students self regulate in chemistry courses: improving the will and skill. DWB Site. Department of Educational Psychology and Center of Curriculum and Instruction, University of Nebraska Lincoln- NE 68588.Available at: dwb.unl.edu/Chau/SelfReg.html

Shabani, H. (2004). Skills education. Tehran: Tehran University Press, SAMT.

Soltani Arabshahi, SK., \& Naeimi, L. (2013). Assessment of the current situation of - self-directed learning skills in medical students. Razi Journal of Medical Sciences, 20(113):10-18.

Torabi, M., Haghani, J., \& Mosavi, E. (2014). Assessment of the habits and study skills in the dental students. Strides in Development of Medical Education, 11(2):244-250.

Valizadeh, L., Fathi Azar, E., \& Zamanzadeh, V. (2008). The relationship between learning characteristics and academic achievement in nursing and midwifery students. Iranian Journal of Medical Education, 7(2): 443-449.

Vrugt, A., \& Oort, FJ. (2008). Metacognition, achievement goals, study strategies and academic achievement: pathways to achievement. Metacognition Learning, 30:123-146.

Winne, PH. (2010). Bootstrapping learner's self-regulated learning. Psychological test and assessment modeling, 52 (4): 472-490.

Wolters, CA. (2003). Regulation of motivation: evaluating an underemphasized aspect of self-regulated learning. Educational Psychologist, 38: 189-205.

Yip, MCW. (2007). Differences in Learning and Study Strategies between High and Low Achieving University Students: A Hong Kong Study. Educational psychology, 27(5): 597-606.

Zimmerman, BJ. (1990). Self- regulated learning and academic achievement: An Overview. Educational Psychologist, 25 (1): 3-17. 